\title{
IRÁN: ¿AMENAZA NUCLEAR?
}

\section{Pablo César ReviLla MonTOYA*}

RESUMEN: El programa nuclear iraní podría ser considerado como una amenaza a la paz y seguridad internacionales. Sin embargo, ¿existirán motivos razonables para considerarlo de esa manera?, ¿qué actores participan directamente en la controversia?, ¿será posible encontrar soluciones a este tipo de situaciones? Estos son los problemas que aquí se plantea resolver.

ABSTRACT: The Iranian nuclear program could be considered as a threat against the peace and the international security. Nevertheless, will reasonable reasons exist to consider it in that way?, which actors directly participate in this dispute?, will be possible to find some solutions to this type of situations?, these are the problems tried to solve by this research.

RÉSUMÉ: Le programme nucléaire iranien pourrait être considéré comme une menace contre la paix et la sécurité internationales. Néanmoins, il existera des motifs raisonnables pour le considérer de cette manière?, quels acteurs participent directement à ce différend?, il sera possible de trouver des solutions à ce type de situations?, ils sont les problèmes que cette recherche on propose de résoudre.

* Licenciado en derecho por la Universidad Nacional Mayor de San Marcos, master en relaciones internacionales y comercio por la Universidad de San Martín de Porres, especialista en defensa nacional por la Universidad Nacional "Federico Villarreal". 
SUMARIO: I. Introducción. II. La controversia suscitada por el programa nuclear iraní. III. Relación entre la fabricación de bombas atómicas y el programa nuclear iraní. IV. Argumentos para considerar al programa nuclear iraní como una amenaza a la paz y seguridad internacionales. V. Condiciones internas que influyen en la toma de decisiones de los principales Estados involucrados. VI. Consecuencias del mantenimiento del programa nuclear iraní. VII. Medidas de fomento a la confianza para una solución pacífica. VIII. Conclusiones.

\section{INTRODUCCIÓN}

Con el fin de la Guerra Fría nació un nuevo orden internacional que trajo consigo una serie de oportunidades para los Estados (como la apertura de mercados), pero también desafíos (como la globalización), riesgos y amenazas (como la proliferación de armas de destrucción masiva, el terrorismo global, el crimen organizado, la corrupción institucionalizada, etcétera).

En ese contexto, algunos Estados, como Irán, han venido desarrollando programas nucleares que podrían ser considerados como una amenaza a la paz y seguridad internacionales. De allí que en nuestra investigación abordaremos tanto el derecho al desarme como las medidas de fomento a la confianza y la seguridad internacional.

\section{LA CONTROVERSIA SUSCITADA POR EL PROGRAMA NUCLEAR IRANÍ}

\section{El programa nuclear iraní}

El programa nuclear iraní tiene como antecedentes dos hechos: los contratos suscritos con Estados Unidos y Francia. En el primer caso, el régimen del rey Pahlavi se comprometió con Estados Unidos a producir 20,000 megavatios de electricidad, así como la construcción de una central nuclear. En el segundo caso, Francia se comprometía, por un lado, a cooperar con el régimen iraní para la construcción de una central nuclear, la cual produciría 6,000 megavatios de electricidad; y por otro lado, Irán se comprometía a enriquecer uranio. Sin embargo, tras la revolución islámica de los ayatolas, se dejaron sin efecto esos compromisos. 
Hay que recordar que Rusia ha sido uno de los principales distribuidores de tecnología nuclear a Irán ${ }^{1}$ desde 1979, incluso en 1995 construyó la planta nuclear de Bushehr que comenzó sus actividades en septiembre de 2002. Sin embargo, en diciembre de ese mismo año, se hicieron públicas fotografías satelitales que revelaron la existencia de instalaciones nucleares en Arak y Natanz.

Posteriormente, Irán aceptó una inspección de la Agencia Internacional de Energía Atómica (AIEA) que, en septiembre de 2003, fija unas semanas de plazo para que Irán pruebe que no está desarrollando bombas atómicas.

En noviembre de 2003, Irán suspende el enriquecimiento de uranio y permite nuevas inspecciones en donde la AIEA asegura no tener pruebas sobre ningún programa de armas; aunque unos meses después, en junio de 2004, la misma agencia critica a Irán por no cooperar completamente con la investigación.

Luego de conversaciones con la Troika (conformada por Alemania, Francia, Reino Unido, la Unión Europea e Irán), Irán suspende el enriquecimiento de uranio como parte del Acuerdo de París del 15 de noviembre de 2004.

Al año siguiente, el 5 de agosto de 2005, Alemania, Reino Unido y Francia, en el marco del Acuerdo de París, entregaron sus propuestas a Irán, las cuales fueron rechazadas por este último, reanudando sus actividades en la planta nuclear de Isfahan, el 10 de agosto del mismo año.

La respuesta de los negociadores no se hizo esperar, el 23 de septiembre de 2005, hicieron público su rechazo publicando una declaración conjunta en el prestigioso diario Le Monde:

Durante cerca de veinte años, Irán ocultó sus actividades relacionadas con el enriquecimiento y las actividades de tratamiento que, en caso de resultar exitosas, le permitirían producir materias físiles para un arma nuclear. Sólo a partir de 2002, cuando se descubrió la magnitud de sus actividades no declaradas, reconoció su existencia y aún así fue necesaria la presión de investigaciones de la AIEA.

1 La colaboración entre Rusia e Irán está basada en el derecho internacional general (derecho de aprovechar la energía atómica con fines pacíficos) y en la Carta del Organismo Internacional de Energía Atómica. 
Finalmente, la controversia se acentúa cuando el 10 de enero de 2006, Irán retiró los precintos de seguridad que mantenían cerrada su planta de enriquecimiento de uranio de Natanz. Este acontecimiento provocó fuertes críticas en Occidente. Las amenazas de Estados Unidos y la Unión Europea de remitir el asunto al Consejo de Seguridad de las Naciones Unidas no surtieron efectos sobre el gobierno de Mahmoud Ahmadinejad.

Es más, las sanciones que el Consejo de Seguridad ha establecido al régimen iraní no han logrado su cometido, es decir, la suspensión de las actividades de enriquecimiento de uranio.

Sin embargo, por lo que se conoce, la naturaleza del programa nuclear iraní es de índole energética, a pesar de ello, las plantas nucleares que se encuentran en construcción no se han inspeccionado todavía.

\section{Posiciones e intereses de las partes involucradas}

\section{A. La República Islámica de Irán}

Para Irán, su programa nuclear tiene fines civiles circunscritos básicamente a generar electricidad o investigación. Su posición se basa en el Tratado de No Proliferación de 1970 (TNP) ${ }^{2}$ cuyo artículo cuarto ${ }^{3}$ prescribe que es un derecho inalienable de todo Estado parte beneficiarse de la energía nuclear para fines pacíficos.

Por otro lado, para Irán, su programa nuclear es una política de Estado cuyo antecedente se encuentra en el gobierno del Muhammad Reza Pahlavi, Sha de Irán, por lo tanto es irreversible. Es propicio recalcar que

2 Abierto a la firma en 1968, el Tratado entró en vigor en 1970.

3 Los dos párrafos del Artículo IV tienen una importancia sustancial y estipulan que: "1. Nothing in this Treaty shall be interpreted as affecting the inalienable right of all the Parties to the Treaty to develop research, production and use of nuclear energy for peaceful purposes without discrimination and in conformity with Articles I and II of this Treaty./ 2. All the Parties to the Treaty undertake to facilitate, and have the right to participate in, the fullest possible exchange of equipment, materials and scientific and technological information for the peaceful uses of nuclear energy. Parties to the Treaty in a position to do so shall also co-operate in contributing alone or together with other States or international organizations to the further development of the applications of nuclear energy for peaceful purposes, especially in the territories of non-nuclear-weapon States Party to the Treaty, with due consideration for the needs of the developing areas of the world". 
hasta hace un par de años Irán planeaba tener para el 2021 un total de 11 reactores nucleares.

Sin embargo, su interés principal es convertirse en una gran potencia regional y en ese sentido tener una capacidad suficientemente disuasiva como para no ser susceptible a ataques externos.

En ese sentido, lo que busca Irán es su propia seguridad y el auto-convencimiento de no ser invadido por Estados Unidos, país que ha tildado a Irán como parte integrante del eje del mal y por tanto susceptible de ser atacado.

Tal vez Irán tenga entre sus planes la negociación de su programa nuclear con un tratado que establezca la renuncia de Estados Unidos al uso de la fuerza en su contra, procurándole garantías de seguridad, tal como lo pide Corea del Norte y alguna vez la Unión Soviética a favor de Cuba como parte de la solución de la crisis de los misiles de 1962.

Sin embargo, "Irán ya ha anunciado que endurecerá su política y cortará toda relación con la AEIA si se discuten y llegan a imponer sanciones contra su régimen a causa del programa nuclear". ${ }^{4}$ A tal respecto, los dirigentes iraníes:

Creen que en el tema de su programa nuclear tienen todas las cartas en sus manos, creen que Irán podría ser como Corea del Norte, un país al que se le permitió, por dejación, convertirse en potencia nuclear. Al mismo tiempo que puede ser también como el Irak de Saddam, que jugó a la mentira y al desafío durante años con la ONU sin sufrir consecuencia alguna. Por último, creen que Irán es un pez demasiado grande para ser tragado con una intervención militar. Si el Irak post-Saddam es una pesadilla, atacar a Irán sería mucho peor. Pero deberían pensárselo dos veces porque podrían estar equivocándose. ${ }^{5}$

\section{B. Estados Unidos de América}

Para la única superpotencia, el programa nuclear iraní tiene fines militares encubiertos y se basa en la falta de apoyo a las inspecciones de la

4 GEES, "Los dados están echados", Libertad Digital, núm. 743, 28 de abril de 2006, p. 1, http://www.gees.org/pdf/2415/.

5 Bardají, Rafael L., "El reto iraní: ¿y ahora qué?", $A B C, 5$ de mayo de 2006, http://www.abc.es/hemeroteca/historico-05-05-2006/abc/Opinion/el-reto-irani-y-ahora -que_1421416930870.html. 
Agencia Internacional de Energía Atómica y el ocultamiento que por años hizo Irán sobre su programa nuclear.

Para Estados Unidos, Irán, como parte del eje del mal, promociona el terrorismo y en tal sentido es una amenaza a la paz y seguridad internacionales. Sin embargo, no descarta una solución diplomática, pero siempre y cuando Irán suspenda el enriquecimiento de uranio.

Estados Unidos pretende que el Consejo de Seguridad siga sancionando a Irán, ya que no ha cumplido con las exigencias de sus resoluciones, en especial la que pide la suspensión del enriquecimiento de uranio.

\section{La Federación Rusa}

Rusia ha sido el principal proveedor de tecnología nuclear a Irán, es sabido que existen contratos para que Rusia construya más centrales nucleares en dicho país.

Por esos motivos, para Rusia una solución diplomática sería la vía correcta para la solución de la controversia. En tal sentido, Rusia propuso que se cree una empresa binacional ruso-iraní que enriquezca uranio en territorio ruso, para abastecer a Irán del combustible para sus plantas nucleares.

Sin embargo, esta interesante propuesta fue rechazada en un inicio por Irán, para luego ser aceptada, aunque inaceptada por Estados Unidos y la Troika.

\section{La República Popular China}

Para muchos analistas, China se ha convertido en la futura superpotencia económica mundial, sin embargo ahora depende en gran medida del petróleo iraní. En ese contexto sería sumamente contraproducente para los intereses chinos un conflicto incluso de medianas proporciones en Irán, ya que sería uno de los países directamente afectados por el evidente aumento de los precios del petróleo, consecuencia evidente del conflicto no deseado.

China recibe de Irán cerca del 13\% de sus importaciones de petróleo. En noviembre de 2004, ambos países firmaron en Pekín un preacuerdo por un valor superior a los 100,000 millones de dólares para que la empresa estatal china Sinopec compre 250 millones de toneladas de gas natural licuado por un periodo superior a 25 años y realice prospecciones en el campo petrolífero de Yadavarán, desde donde se exportarán a Chi- 
na 150,000 barriles de crudo diarios. Ese preacuerdo, firmado como memorando de entendimiento, prevé ventas anuales de 10 millones de toneladas de gas natural licuado e implica una importante inversión en la ampliación de la flota petrolera iraní. Adicionalmente, comprende la participación china en proyectos como el trazado de oleoductos y la industria petroquímica y de gas, y abarca el suministro de materiales para la industria eléctrica en la ciudad de Arak. Incluye también la construcción de algunas líneas del metro de la capital, la segunda de ellas encargada a Norinco, empresa estrella del complejo militar e industrial chino. Un proyecto ya cerrado es el firmado en enero de 2006, por un valor superior a los 30 millones de dólares, para el mantenimiento operativo de la plataforma petrolífera de Alborz, en el Mar Caspio. ${ }^{6}$

Para China, la solución de la controversia debe pasar por la verificación y el acuerdo dentro del marco del Organismo Internacional para la Energía Atómica, a la no imposición de sanciones, y a la no amenaza del uso de la fuerza o a su uso decidido. ${ }^{7}$

\section{E. La Troika (Francia, Alemania y el Reino Unido)}

La denominada Troika es el grupo negociador europeo conformado por Francia, Alemania y el Reino Unido que asumieron las negociaciones con Irán a raíz del descubrimiento de su programa nuclear en el 2003. No obstante, sus esfuerzos no devinieron en logros significativos, tan sólo una moratoria sobre el enriquecimiento de uranio que duró menos de un año, cuyo marco legal es el acuerdo de París.

Lamentablemente, en agosto del 2005 Irán se retiró de las negociaciones aduciendo que las propuestas europeas eran poco satisfactorias.

La Troika sugiere que Irán debe suspender su enriquecimiento de uranio, y propone incentivos que han sido rechazados enérgicamente por Irán, ya que los considera intrascendentes.

La Troika insiste en una solución negociada, sin embargo, ante la intransigencia iraní, exigen sanciones más severas por parte del Consejo de Seguridad. Sin embargo, difiere con Estados Unidos, ya que optan por una posición más conciliadora.

6 Soto, Augusto, "China ante la crisis iraní”, ARI, Real Instituto Elcano, núm. 49/2006, 24 de abril de 2006, p. 2, http://www.realinstitutoelcano.org/analisis/960/Soto $\% 20 P D f . p d f$.

7 Ibidem, p. 1. 
Con bien se ha dicho, "no es la primera vez que europeos y americanos difieren sobre las terapias a aplicar a problemas que son percibidos de igual manera". 8

\section{F. El Consejo de Seguridad}

Ante las presiones estadounidenses, el Consejo de Seguridad tuvo una reunión en la que se acordó una declaración de su presidente, ${ }^{9}$ en la que se pide la suspensión de todas las actividades relacionadas con el enriquecimiento de uranio y el reprocesamiento, incluidas las de investigación y desarrollo, la que será verificada por la Agencia Internacional de Energía Atómica.

Tras una serie de reuniones entre los representantes permanentes del Consejo de Seguridad, más Alemania y el alto representante de la Unión Europea, se llegó a un consenso para aprobar una Resolución ${ }^{10}$ que pidió, entre otras cosas, que Irán adopte las medidas solicitadas por la Junta de Gobernadores del OIEA en su resolución GOV/2006/14, sobre medidas de confianza y suspensión de actividades de enriquecimiento de uranio.

Sin embargo, Irán no cumplió con la resolución, lo que conllevó a que el Consejo emitiera una segunda, ${ }^{11}$ en la que, actuando con arreglo al artículo 41 del capítulo VII de la Carta de las Naciones Unidas, ${ }^{12}$ se sanciona a Irán con una serie de restricciones a la importación de materiales y tecnología nuclear, así como de asistencia y capacitación; asimismo, se decide el congelamiento de activos financieros a las entidades y personas que conforme al anexo de la Resolución participan en el programa nuclear iraní.

Lamentablemente, Irán no cumplió con la Resolución 1737 (2006), lo que llevó al Consejo a ampliar las sanciones; ${ }^{13}$ sin embargo, en la nue-

8 Bardají, Rafael L., "Irán, Marte y Venus", op. cit., nota 5.

9 S/PRST/2006/15, Declaración del Presidente del Consejo de Seguridad, 29 de marzo de 2006.

10 S/RES/1696 (2006), 31 de julio de 2006.

11 S/RES/1737 (2006), 27 de diciembre de 2006.

12 Sobre medidas que no impliquen el uso de la fuerza armada, es que el Consejo podrá decidir emplear para hacer efectivas sus decisiones.

13 S/RES/1747 (2007), 24 de marzo de 2007. 
va resolución se anexan los "elementos de un acuerdo a largo plazo" con Irán, sobre cooperación energética, nuclear, política y económica.

Algunos analistas ${ }^{14}$ piensan que fue un error enviar el caso al Consejo de Seguridad, ya que Rusia y China argüirán que enriquecer uranio no está prohibido por el Tratado de No Proliferación, sino por un protocolo adicional que Irán firmó en 2004 y cuyo valor jurídico no puede ser el mismo que el del Tratado.

\section{G. La Junta de Gobernadores de la Agencia Internacional de Energía Atómica}

La Junta de Gobernadores es el órgano colegiado de la Agencia Internacional de Energía Atómica. Sus decisiones deben ser acatadas por todos los miembros del Tratado de No Proliferación Nuclear.

En su resolución GOV/2006/14 del 4 de febrero de 2006, la Junta de Gobernadores consideró necesario que Irán restablezca la suspensión plena y sostenida de todas las actividades relacionadas con el enriquecimiento y las actividades de reprocesamiento, incluidas las actividades de investigación y desarrollo, pero también que aplique las medidas de transparencia.

Desde entonces el director general del OIEA ha venido realizando una serie de informes sobre la situación en Irán. Por ejemplo, en el informe del 22 de febrero de 2007 (GOV/2007/8) se afirmó que Irán no ha suspendido sus actividades relacionadas con el enriquecimiento.

Sin embargo, a la fecha los inspectores del OIEA no han encontrado ninguna pista sobre un programa de construcción de armas atómicas en Irán, aunque, en honor a la verdad, no se han podido continuar las inspecciones por falta de apoyo de Irán.

\section{Instrumentos internacionales aplicables al programa}

nuclear iraní

Las armas nucleares están sujetas a diversos instrumentos universales de control. Los más importantes son el Tratado de No Proliferación (TNP) y el Tratado de Prohibición Completa de los Ensayos Nucleares (TPCEN). 
El TNP está abierto a la firma desde el 1o. de julio de 1968 en Londres, Moscú y Washington. Entró en vigor el 5 de marzo de 1970 con una duración inicial de 25 años. Posteriormente, en la Conferencia de Examen y Prórroga de 1995, el Tratado fue prorrogado indefinidamente. Por lo que hoy en día, se puede afirmar que el Tratado de No Proliferación tiene una membresía casi universal, y a diferencia de otros, debe informarse de su retiro con tres meses de anticipación

El TNP distingue entre Estados Poseedores de Armas Nucleares (EPAN) y Estados No Poseedores de Armas Nucleares (ENPAN). Los primeros se definen como aquellos Estados que explotaron artefactos nucleares antes del 1o. de enero de 1967 y comprenden a China, Francia, Estados Unidos, la Unión Soviética (ahora Federación de Rusia) y el Reino Unido. Los ENPAN son aquellas partes que han renunciado a la adquisición de armas nucleares. ${ }^{15}$

Entre las principales disposiciones del TNP, se mencionan a las siguientes: ${ }^{16}$

- Los Estados Poseedores de Armas Nucleares (EPAN) tienen prohibido transferir o ayudar a otros a adquirir armas nucleares y tecnologías relacionadas o tener control sobre éstas, mientras que los Estados No Poseedores de Armas Nucleares (ENPAN) tienen prohibido recibir o desarrollar armas nucleares.

- Se reconoce el derecho de todas las partes a investigar, producir y utilizar energía nuclear con fines pacíficos, siempre y cuando cuente con la supervisión del Organismo Internacional de Energía Atómica. Asimismo, permite a los EPAN ayudar a los ENPAN en la explotación pacífica de la tecnología nuclear.

- Por último, llama a todas las partes a negociar medidas de buena fe relacionadas con el desarme nuclear, así como un tratado sobre desarme general y completo bajo un control internacional estricto y eficaz.

15 Revilla Montoya, Pablo, "Irán: ¿amenaza nuclear o uso pacífico de la tecnología nuclear?", GIEPERU, 16 de enero de 2006, http://www.gieperu.org/opiniones/revilla/ iran.htm.

16 Idem. 


\section{RELACIÓN ENTRE LA FABRICACIÓN DE BOMBAS ATÓMICAS Y EL PROGRAMA NUCLEAR IRANÍ}

Todos los países del mundo tienen derecho a disfrutar del uso pacífico de la tecnología nuclear, pero a veces cuando un Estado tiene una alta capacidad nuclear se ve tentado en fabricar una bomba atómica.

La tecnología nuclear no sólo sirve para generar electricidad (o desarrollar bombas nucleares), sino también tiene otros fines pacíficos que ayudan al desarrollo y crecimiento de los países. Por ejemplo, es usual la aplicación de radiosótopos para la conservación de alimentos o la fertilidad de los suelos. En medicina tiene aplicaciones terapéuticas, por ejemplo, el yodo radiactivo sirve para tratar casos de cáncer de tiroides.

Existen varios tipos de plantas nucleares que utilizan combustible nuclear o uranio enriquecido, desde las que emplean reactores para investigación hasta las que precisamente enriquecen uranio.

Para tener todos los elementos de análisis, en este apartado vamos a explicar las etapas en la elaboración de bombas atómicas y el tiempo que le tomaría a Irán desarrollarlas, asumiendo que tenga la intención de hacerlas.

\section{Etapas en la elaboración de bombas atómicas ${ }^{17}$}

Con unos cuantos kilos de uranio 235 enriquecido, y mediante la tecnología adecuada se podría desarrollar una bomba atómica, pero obtener ese combustible es muy complicado ya que el uranio natural está compuesto por $99.3 \%$ del isótopo uranio 238 y $0.7 \%$ de uranio 235 , su separación del uranio 235 es un problema tecnológico complejo.

Para enriquecer uranio se requiere primero obtenerlo de las minas o comprarlo, con él se produce un óxido de uranio concentrado (yellowcake) para luego someterlo a una temperatura de $64^{\circ} \mathrm{c}$. Convirtiéndolo en un gas llamado hexafluoruro de uranio, que es introducido en máquinas centrífugas para finalmente obtener el uranio enriquecido.

El uranio enriquecido de bajo nivel es usado como combustible en los reactores nucleares de investigación. Pero el uranio enriquecido de alto nivel puede ser utilizado para crear armas nucleares.

17 Sobre el tema véase $h t t p: / / n e w s . b b c . c o . u k / h i / s p a n i s h / s c i e n c e / n e w s i d$ 4610000/46 10188.stm. 
Es conocido que en la planta de Isfahán se lleva a cabo la conversión de polvo de uranio concentrado en tetrafluoruro (uf4) y más adelante en hexafluoruro de uranio (uf6). Finalmente, en la planta de Natanz se introduce este gas en centrifugadoras para conseguir el uranio enriquecido.

\section{Tiempo que le tomaría a Irán desarrollar bombas atómicas}

Desarrollar una bomba atómica desde el principio no es algo que pueda realizarse de la noche a la mañana. Las estimaciones de los expertos señalan un plazo de tres años (2009 en caso de Irán), aproximadamente. Hay un número de pasos necesarios hacia la fabricación de una bomba nuclear de uranio, a saber: explotación minera, conversión, enriquecimiento y fabricación. Las armas nucleares requieren un tipo específico de uranio (U-235), el cual es poco frecuente encontrarlo en la naturaleza, por lo que un lento y dificultoso proceso es necesario para separar el U-235 del U-238, para acumularlo dentro del material en forma de bomba. Asimismo, el uranio para ser utilizado en la construcción de un arma nuclear se debe enriquecer hasta el 90\%. El tipo más simple del arma nuclear es el arma de fisión, la cual requiere aproximadamente 50 kilogramos (110 libras) de uranio altamente enriquecido (UAE), e implicaría esencialmente tirar dos masas de UAE (25 kilogramos cada una) una contra otra para crear una masa crítica y así una explosión nuclear. Hasta la fecha, Irán ha enriquecido una cantidad minuciosa de uranio de $4.6 \%$ por minuto, un nivel que es usable para la energía atómica, a este paso, le tomará más de 13 años a Irán acumular suficiente UAE para terminar de construir un arma nuclear. Sin embargo, Irán ha anunciado su intención a comenzar a construir una cascada de 3,000 centrifugadoras antes de fin de 2006. ${ }^{18}$

\section{ARGUMENTOS PARA CONSIDERAR AL PROGRAMA NUCLEAR IRANÍ COMO UNA AMENAZA A LA PAZ Y SEGURIDAD INTERNACIONALES}

Creemos que existe una responsabilidad mundial de prevención de conflictos, en especial los que puedan ser considerados un peligro a la paz y seguridad internacionales. Y definitivamente, prevenir que los

18 Martin, Matt, "Iran: Questions Answered", Think, the Stanley Foundation, http:// www.stanleyfoundation.org/articles.cfm? $i d=356$. 
Estados obtengan la "gran bomba" debe ser prioritario en la agenda internacional, ya que las armas nucleares, como las armas químicas y las biológicas (o bacteriológicas) son armas de destrucción masiva y todas ellas violan el derecho internacional humanitario, desde que no distinguen entre población civil, combatientes o heridos, básicamente, violan el principio de humanidad y distinción.

Existen argumentos fidedignos para suponer que en un futuro no muy lejano Irán esté en posibilidades de obtener armas nucleares. Esta aseveración se basa en argumentos que desarrollaremos en este apartado.

\section{Escasa o nula necesidad de Irán de contar con un sector eléctrico basado en la energía nuclear}

Siendo Irán el 2o. exportador de petróleo del mundo, un programa nuclear energético crea fundadas suspicacias; sin embargo, hay que tomarlo en su verdadera dimensión. A continuación, siguiendo a de Quinto, ${ }^{19}$ explicaremos los motivos por los que creemos que Irán no tiene una necesidad urgente de contar con un sector energético basado en la energía nuclear.

En primer lugar, creemos que no es el momento tecnológico para la energía nuclear, ya que ha sido un error económico. Por otro lado, la dependencia energética exterior no debe ser motivo de preocupación en Irán, ya que no tiene compromisos de reducción de gases de efecto invernadero derivados del Protocolo de Kyoto.

El sector eléctrico iraní, ni siquiera sumando el de los países vecinos, tiene tamaño suficiente para justificar la amortización de las instalaciones para llevar a cabo el ciclo de fabricación de combustible nuclear completo. Muchos países que tienen centrales nucleares para la generación eléctrica no fabrican combustible nuclear o no realizan el ciclo completo.

Finalmente, es sabido que las centrales nucleares requieren de un tratamiento especializado de los residuos nucleares, y esto implica disponibilidad de tecnología y altos costes.

19 Quinto, Javier de, “Ocho razones por las que el sector eléctrico iraní puede pasar sin la energía nuclear", UNISCI Discussion Papers, núm. 10, enero de 2006, http:// www.ucm.es/info/unisci/UNISCI10Quinto.pdf. 
Desde el punto de vista de la política tecnológica, para Irán es un error apostar por el desarrollo nuclear, puesto que un país cómo Irán debiera apostar por el desarrollo de las industrias basadas en media intensidad tecnológica, y por ello, su política de desarrollo tecnológico debiera considerar los siguientes aspectos: ${ }^{20}$

- Dada la globalización de los mercados, no es factible competir con la UE, Estados Unidos, Japón o Rusia en segmentos de alta intensidad tecnológica.

- El mercado interior iraní es demasiado pequeño para actuar como motor del desarrollo tecnológico.

- Dados el nivel de formación (bueno, pero no excelente) y las dificultades de acceso y comunicación con otras instituciones tecnológicas internacionales, las dificultades en el desarrollo de la alta tecnología es evidente.

- El desarrollo tecnológico energético iraní debiera orientarse a donde están sus ventajas en recursos primarios: hidrocarburos y energía solar.

En vista a lo anterior, si el gobierno iraní persevera en su intención de desarrollar el proceso de fabricación del combustible nuclear de forma integral, sólo cabe pensar que está cometiendo un error desde el punto de vista energético y de política tecnológica o que su propósito es militar.

\section{Posición iraní respecto al Estado de Israel}

En las relaciones internacionales, los gobernantes deben tener bastante prudencia a la hora de expresarse de los Estados. Sin embargo, el estilo de Ahmadinejad es confrontacional.

El 27 de octubre de 2005, en una conferencia titulada "El mundo sin el sionismo", a la que asistieron 3,000 estudiantes, el presidente de Irán afirmó que Israel "debería ser borrado del mapa".

El 9 de diciembre de 2005, en una conferencia islámica internacional en la Mecca, Ahmadinejad dijo a periodistas: "ahora que ustedes creen que los judíos fueron oprimidos, ¿por qué los musulmanes palestinos deben pagar el precio? Ustedes los oprimieron, así que cedan un pedazo de 
tierra europea al régimen sionista para que establezca allí el gobierno que quiera". ${ }^{21}$

En un discurso televisado dado el 14 de diciembre de 2005, en la ciudad iraní de Zahedan, la prensa reportó que Ahmadinejad hizo las siguientes declaraciones con respecto al holocausto judío:

Según la prensa iraní:

Si los europeos están diciendo la verdad en sus afirmaciones de que ellos asesinaron a seis millones de judíos en el holocausto durante la Segunda Guerra Mundial - lo cual parece cierto porque insisten en ello, y arrestan y encarcelan a aquellos que lo niegan-, entonces, ¿por qué la nación palestina debe pagar por ese crimen? ¿Por qué han venido al corazón del mundo islámico y cometen crímenes contra los palestinos usando sus bombas, cohetes, misiles y sanciones?... Los mismos países europeos han impuesto un régimen sionista establecido ilegalmente sobre la nación palestina. Si ustedes han cometido los crímenes, entonces, denle ustedes un pedazo de su tierra en algún lugar de Europa o América y Canadá o Alaska para que allí instalen su propio Estado. Entonces la nación iraní no tendrá objeciones, no organizará protestas el día de Al Quds (día de Jerusalén) y apoyará su decisión. ${ }^{22}$

\section{Según CNN:}

Ellos han inventado una leyenda en la cual los judíos fueron masacrados y la pusieron por encima de Dios, las religiones y los profetas. En occidente se le ha dado mayor significado al mito del genocidio judío, aún más que a Dios, la religión y los profetas, y se trata de manera severa a aquellos que niegan esta leyenda pero no hacen nada a aquellos que niegan a Dios, la religión y los profetas. Si ustedes quemaron a los judíos, ¿por qué no le dan un pedazo de Europa, los Estados Unidos, Canadá o Alaska a Israel? Nuestra pregunta es, si ustedes cometieron el crimen, ¿por qué una nación inocente como Palestina tiene que pagar por ese crimen? ${ }^{23}$

21 Véase Tait, Robert, "Israel should move to Europe, says Iran's leader", The Guardian, 9 de diciembre de 2005. http://www.guardian.co.uk/iran/story/0,12858,1663440, 00.html.

22 Islamic Republic News Agency, "Polling only Solution to Palestine Problem, President", miércoles 14 de diciembre de 2005. La declaración puede ser encontrada en: http://www.globalsecurity.org/wmd/library/news/iran/2005/iran-051214-irna02.htm.

23 CNN, "Iranian Leader: Holocaust a 'Myth", miércoles 14 de diciembre de 2005. http://www.cnn.com/2005/WORLD/meast/12/14/iran.israel/index.html. 
Posteriormente, en unas respuestas escritas a preguntas de los lectores aparecidas el 1o. de enero de 2006, en varios periódicos iraníes, Ahmadineyad dijo que la creación de Israel después de la Segunda Guerra Mundial había "matado dos pájaros de un tiro" para Europa. Por una parte, había conseguido "barrer a los judíos de Europa y al mismo tiempo crear un apéndice europeo con una naturaleza sionista y antiislámica en el corazón del mundo islámico". También comparó al sionismo con el fascismo: "El sionismo es una ideología occidental y una idea colonialista... y ahora mismo masacra a musulmanes con dirección directa y ayuda de Estados Unidos y una parte de Europa... El sionismo es básicamente un nuevo fascismo". También cuestionó una vez más por qué la investigación y el debate sobre cuántos judíos murieron en el holocausto era tabú y preguntó si era verdad que millones de judíos habían muerto a manos de Alemania. ${ }^{24}$

\section{Radicalismo teocrático del Estado iraní o raison d'état}

Se ha hablado mucho sobre el supuesto radicalismo que conlleva una religión que copa las estructuras mismas del Estado, más aún si los chítas tienen un pasado bastante controvertido. Sin embargo, nos preguntamos si la situación en Irán es mero radicalismo teocrático o es una situación que deviene del más puro interés del Estado o la doctrina de la raison d'état.

Lo cierto es que con unos cuantos misiles nucleares Irán sabe que podría dictar el escenario estratégico del Golfo Pérsico intimidando a los jeques del Golfo en materia de disputas fronterizas y producción petrolera, y reclamando la dirección en la lucha islamista contra Israel. Una "bomba persa" logra prestigio nacional y erradica a los disidentes en casa, al tiempo que garantiza suficiente inestabilidad para mantener disparados los precios del petróleo. ${ }^{25}$

En ese sentido, consideramos que existen motivos que van más allá de lo teocrático. Creemos que Irán actúa pensando más en su subsistencia que en el legado religioso chí́ta.

24 Véase http://es.wikipedia.org/wiki/Mahmud_Ahmadineyad.

25 Davis Hanson, Víctor, "El alacrán nuclear de Irán”, Colaboraciones, núm. 1053, 28 de junio de 2006, p. 2, http://www.gees.org/pdf/2667/. 


\section{Corrupción, proliferación nuclear y el terrorismo global}

Es sabido que el presidente Mahmud Ahmadinejad tomó el poder con la consigna de luchar contra la corrupción generalizada del régimen de los ayatolas. Se dice que Irán, junto con Corea del Norte, es uno de los Estados más corruptos del planeta, en donde la corrupción está más que institucionalizada, ya que involucra a toda la estructura del Estado.

De allí que surja una comprensible desconfianza hacia el régimen de los ayatolas. Independientemente de su discurso antisemita, Ahmadinejad no puede controlar la corrupción interna, por lo que se puede pensar que el terrorismo global podría adquirir algún tipo de tecnología nuclear iraní, para realizar algún atentado de terrorismo nuclear.

El terrorismo nuclear comprende cuatro tipos diferentes de actividad terrorista: ${ }^{26}$

- El robo y utilización de un artefacto nuclear intacto.

- El robo o la adquisición de material fisionable que luego se usará para hacer un arma nuclear.

- Ataques a reactores u otras instalaciones nucleares con el objetivo de causar contaminación radiológica en las áreas circundantes.

- El uso de material radiológico para hacer un artefacto de dispersión radiológica (ADR).

De estas, la ADR o "bomba sucia" es la más fácil de conseguir y la que tiene más probabilidades de ocurrir, pero el robo de un artefacto nuclear intacto o del material fisionable con el cual se pueda confeccionar un artefacto nuclear representa los peligros más mortales. El uso más notable de material radiológico ocurrió en 1995, cuando separatistas chechenos dejaron una caja de cesio en un parque de Moscú.

26 Cameron, Gavin, "Terrorismo nuclear: ¿Armas para vender o armas para comprar?", Agenda de la Política Exterior de Estados Unidos de América, eJournal USA, Departamento de Estado de Estados Unidos, Oficina de Programas de Información Internacional, marzo de 2005, p. 17. 


\section{CONDICIONES INTERNAS QUE INFLUYEN \\ EN LA TOMA DE DECISIONES DE LOS PRINCIPALES \\ ESTADOS INVOLUCRADOS}

\section{Influencia en la toma de decisiones en Irán}

Irán es un país peculiar, de población mayoritariamente chiíta, en donde las motivaciones religiosas son las mejores excusas para cualquier reforma o lucha.

En Irán, la opinión pública es importante, siempre es bueno contar con una base social amplia y la legitimidad suficiente para poder gobernar. Sin embargo, su importancia no es fundamental, como alguna vez expuso Mohammad Jatami, ex presidente iraní: "primero es Dios, luego el líder ${ }^{27}$ y finalmente las demandas de los votantes". ${ }^{28}$

La complejidad del sistema político iraní evidencia la existencia de un poder detrás del poder. Si bien es cierto que Irán cuenta con un presidente de la República y un Parlamento elegidos mediante sufragio universal, existen otras instituciones que se encuentran por encima de ellos.

La Constitución iraní, y concretamente su artículo 93, establece que "el Parlamento Islámico no tiene validez legal sin la existencia del Consejo de Guardianes, salvo en la aprobación de la acreditación de los candidatos y la elección de los seis juristas del Consejo de Guardianes". Las funciones y poderes del Consejo de Guardianes se establecen en el mismo artículo de la Constitución, en el que se dice que:

Con el objeto de salvaguardar los mandatos del Islam y la Constitución en caso de divergencia entre las leyes aprobadas por el Parlamento Islámico y dichos mandatos, se crea un consejo llamado Guardián, compuesto por: 1) seis Foqaha-ye Adel (ecuánimes expertos en el conocimiento de la ley islámica) conocedores de las necesidades y problemas del momento, cuya elección es a cargo del guía (o Vali-ye Faqi, que es el jefe supremo de la comunidad, y cuyos decretos se consideran divinos y por tanto infalibles); y 2) seis juristas expertos en distintas ramas del derecho, escogidos entre

27 Refiriéndose a Jamenei.

28 CIBOD, "Mohammad Jatami", Copyright Fundación CIDOB, 10 de agosto de 2001. http://www.cidob.org/bios/castellano/lideres/j-012.htm. 
juristas musulmanes y presentados por el jefe del Poder Judicial al Parlamento Islámico, quien los elegirá por votación. ${ }^{29}$

Entonces, el que ejerce el poder real y efectivo en Irán es el líder supremo o Rahbar-e Moazam el ayatollah Hodjatoleslam Sayyed Mohammad Ali Hoseyn Jamenei, quien reemplazó al ayatollah Jomeini.

De acuerdo con la Constitución iraní, ${ }^{30}$ el líder supremo de Irán es responsable de la delineación y supervisión "de las políticas generales de la república islámica de Irán”. En ausencia del líder supremo, se nombra a un consejo de líderes religiosos. El líder supremo es comandante en jefe de las fuerzas armadas y controla las operaciones de inteligencia y la seguridad de la República Islámica. Él tiene, por sí mismo, la autoridad de declarar la guerra, así como la capacidad de designar y despedir a los líderes judiciales, de las redes de radio y televisión estatales y al líder máximo del Cuerpo de Guardias de la República Islámica. Designa a seis de los doce miembros del Consejo de Guardianes. Él y el consejo de líderes religiosos, son elegidos por la Asamblea de Expertos, ${ }^{31}$ con base en sus calificaciones y a la alta estima popular que se les profese. ${ }^{32}$

A pesar de ello, la figura del presidente (de Ra'is-e Jomhour) es importante. Después del líder supremo, el presidente de Irán es el funcionario más alto del país. Es el responsable de que la Constitución sea obedecida. Es, además, el jefe del Ejecutivo. Haciendo notar, que a diferencia de lo sucedido en otros países, no es el jefe de las fuerzas militares. Según la ley, todos los candidatos presidenciales deben ser aprobados por el Consejo de Guardianes antes de que formalicen su candidatura. Una vez confirmados como candidatos, el presidente es elegido por mayoría absoluta en sufragio universal para un término de cuatro años. ${ }^{33}$

29 Farzamnia, Nadereh, "La Constitución iraní: un círculo vicioso", ARI, Real Instituto Elcano, núm. 20, 17 de febrero de 2004. http://www.realinstitutoelcano.org/anali sis/412.asp.

30 Véase http://www.salamiran.org/IranInfo/State/Constitution/.

31 La Asamblea de Expertos, que tiene sesiones semanales, consiste de 86 clérigos "virtuosos y doctos" elegidos por el público para un periodo de ocho años. Igualmente que en las elecciones presidenciales y parlamentarias, el Consejo de Guardianes determina elegibilidad para candidatura en esta asamblea. Los miembros de la Asamblea de Expertos, asimismo, eligen al líder supremo dentro de sus propios miembros y lo reconfirman periódicamente. Véase http://es.wikipedia.org/wiki/Ir\%C3\%Aln.

32 Véase http://es.wikipedia.org/wiki/Ir\%C3\%Aln.

33 Idem. 
Ahmedinejad incluye un énfasis ideológico en su política. Para el presidente iraní existe una necesidad de retornar a los valores de la revolución chiíta y del Islam, que según él han sido abandonados en los últimos años, y la preparación de las condiciones para el retorno del mehdi. ${ }^{34}$ Estas concepciones de hecho están dirigidas a las capas más humildes de la población.

Al mismo tiempo, se están perfilando los siguientes indicios de que el nuevo gobierno está actuando para reducir aún más la libertad de expresión:

a) Ahmedinejad ha ordenado (según una publicación del periódico Iran, 19 de diciembre 2005) en vigencia de su carácter de titular del Consejo Supremo de la Revolución Cultural, que la ley islámica sea implementada en la práctica, cumpliendo la ordenanza que prohíbe hacer oír música occidental en los medios iraníes de comunicación (aparentemente, esta ordenanza no esta siendo implementada).

b) Según informes cada vez más numerosos, se están clausurando los cafés cibernéticos, debido a "la desobediencia a las leyes de filtrado y uso de equipo satelital ilegal". Según afirmara Shirin Abadi, una activista de los derechos humanos (y ganadora del premio Nobel) el nuevo gobierno ha bloqueado todas las páginas Web dedicadas a temas relacionados con la mujer, aparte de confiscar todos los trabajos de literatura y arte que tuviesen un mensaje laico, feminista o nihilista.

c) En los últimos meses se ha llevado a cabo una serie de detenciones, juicios y condenas de prisión contra factores identificados con el bando reformista (ex miembros del majles, estudiantes y miembros de los medios de comunicación).

Se puede observar que la política de Ahmedinejad, en el ámbito interno, está orientada sobre todo a plasmar y reforzar su base de fuerza pública, en particular entre las capas menos pudientes de la población.

Dentro de este marco, el presidente iraní actúa de la siguiente manera:

- Está impulsando una concepción islamista, cuasisocialista y antioccidental, con una ideología similar a la de Jomeini, en los inicios de la revolución, pero que se diferencia de forma significativa de las concepciones de sus antecesores en el cargo (Jatami y Rafsanjani),

34 El imán desaparecido que, según la concepción chiíta, está previsto que retornará cuando sea el fin de los días. 
que generalmente impulsaron una concepción económica liberal, y tendían a presentar una relativa apertura respecto a occidente.

- Está efectuando políticas populistas orientadas a favorecer a los sectores mas débiles de la población, postergando el tratamiento de los problemas fundamentales de la economía, lo que a corto plazo podría significar el pago de un elevado precio también entre las capas menos pudientes.

- Se dirige a estratos religiosos mesiánicos, mucho más vigorosos en el seno de las capas menos pudientes y de la periferia.

Ahmedinejad actúa de cara a la periferia, en el eje que rodea a Teherán, para superar los obstáculos puestos por otros organismos centrales del gobierno y para alejarse de la imagen corrupta que han adquirido estos organismos, o porque él detecta en la periferia un potencial de desafío para la estabilidad del régimen.

Simultáneamente, por lo menos por ahora, el presidente se cuida de no abrir un frente interno adicional mediante un cumplimiento más estricto de medidas en el terreno religioso y social, que podrían ir demasiado lejos e incluso originar una efervescencia en el seno de sectores de la población que no se identifican con el régimen ni con sus valores, menos aún con la concepción del presidente. Por otro lado, también está aplicando una política de mano dura contra opositores potenciales.

Por otro lado, el desenvolvimiento del presidente Mahmud Ahmedineyad, en el sistema político, le está creando antagonismos que se extralimitan, del diálogo crítico que caracteriza la política iraní, más aún en un periodo en que su gran mayoría está controlada por el bando conservador, esto se refleja en luchas de fuerza personales e interorganizacionales por la obtención de la influencia y la participación en los procesos de toma de decisiones y en el control de bienes políticos y económicos, aunque es posible que también existan discrepancias más profundas - incluso en el seno del bando conservador mismo - respecto a cómo debe desenvolverse el país.

La agenda islámica popular impulsada por Ahmedinejad implica un verdadero desafío para sus críticos y opositores internos, que podrían ser concebidos como menos ortodoxos o patriotas que él, o como quienes están actuando para hacer fracasar sus iniciativas aparentemente destinadas a beneficiar al hombre común de la calle y a reforzar al régimen y a sus valores. 


\section{Influencia en la toma de decisiones en Estados Unidos}

El 2006 fue un año electoral en Estados Unidos. El pueblo estadounidense otorgó a los demócratas una mayoría parlamentaria. En esos meses el gobierno del presidente George W. Bush trató de no cometer algún error que afectara al estadounidense promedio. Esta situación complicó notablemente el accionar estadounidense en la controversia suscitada por el programa nuclear iraní.

Así pues, la opinión pública americana vive la situación del mundo actual de forma desigual a como se percibe en Europa. Una encuesta hecha en Washington, realizada a nivel nacional por el Public Opinion Strategies, ofrece el siguiente cuadro: un $63 \%$ de encuestados está informado sobre Irán frente a un $18 \%$ que sabe poco al respecto; un $94 \%$ está en desacuerdo con la política iraní, de los cuales un $88 \%$ en firme desacuerdo; un $78 \%$ está preocupado por lo que hace Irán; y un $37 \%$ pediría que los aliados presionaran más a Teherán; un 34\% que la ONU impusiera sanciones; un $12 \%$ que se apoyara abiertamente a los opositores al régimen de los ayatolas; y un $10 \%$ que se realizara una intervención militar limitada. Ahora, no en un hipotético futuro, sino sobre el mañana, si Irán estuviera a punto de ser potencia atómica, un 46\% apoyaría una acción militar unilateral, aunque un 56\% preferiría que Estados Unidos actuara con sus aliados. ${ }^{35}$

\section{CONSECUENCIAS DEL MANTENIMIENTO DEL PROGRAMA NUCLEAR IRANÍ}

El mantenimiento del programa nuclear iraní podría traer como consecuencias una serie de sanciones económicas o militares, incluidos los ataques preventivos o una invasión, ${ }^{36}$ que pueden ser desastrosos tanto para el pueblo iraní como para las relaciones internacionales. En un escenario de guerra, la población civil es la que sufre las peores consecuencias, desde crímenes de guerra hasta graves necesidades humanitarias como hambre, desplazamiento, expulsión o éxodo de refugiados.

35 Bardají, Rafael L., "Irán, Marte y Venus", op. cit., nota 5.

36 Independientemente de la legalidad internacional dibujada en el Consejo de Seguridad. 
En el supuesto de que el Consejo de Seguridad sancionara con un embargo económico a Irán, segundo productor mundial de petróleo, podría acarrear mayores problemas, tanto económicos como políticos, para la comunidad internacional.

Sin embargo, para algunos "los 12-15 dólares de alza del precio que conllevaría el corte del suministro de crudo iraní ya han sido aplicados por las compañías previsoramente", ${ }^{37}$ aunque China, el principal comprador del crudo iraní no piensa lo mismo.

Como nuevo actor global que es, hoy China se aventura a actuar en las zonas donde sus grandes intereses corren altísimos riesgos. En este particular pulso entre Estados Unidos e Irán, Zhongnanhai sabe que Washington es consciente de una China que no puede ver muy mermadas sus perspectivas de aprovisionamiento energético por el bien de la entrelazada economía de ambos. Y porque añadidamente, un ataque, una ocupación o un cambio de régimen provocado en Irán no conduciría necesariamente a un refuerzo de la hegemonía estadounidense del petrodólar. De acometerse, un abrupto cambio en Irán no daría espacio para una suerte de reparto de la gestión entre los miembros permanentes del Consejo de Seguridad. No es una opción realista porque contiene dos inflamables despropósitos. Primero, porque Irán o la genérica red de Al-Qaeda podrían allí sí coincidir y albergar planes inconexos pero efectivos para obstruir parte de la producción de petróleo del Golfo Pérsico. Y segundo, porque de prosperar meridianamente un ataque o un cambio de régimen, China, por la fuerza de las cosas, se vería forzada a aparecer interesada en reforzar sus intereses inmediatos, esto es, su aprovisionamiento energético: una imagen dañina a su noción de largo plazo. De atacar a Irán, Estados Unidos tampoco será secundado por la opinión pública mundial - otra cosa son los gobiernos aliados_-, e inevitablemente cabrá esperar unos imprevisibles ataques de represalia. ${ }^{38}$

37 Bardají, Rafael L., "El reto iraní: ¿y ahora qué?”, op. cit., nota 5.

38 Soto, Augusto, op. cit., nota 6, p. 3. 


\section{MEDIDAS DE FOMENTO A LA CONFIANZA PARA UNA SOLUCIÓN PACÍFICA}

\section{Medidas de fomento a la confianza y los programas nucleares}

\section{A. El paradigma argentino-brasileño}

Brasil y Argentina tuvieron en el pasado un programa nuclear encaminado a la construcción de armas atómicas. Afortunadamente, se dieron cuenta que sería mejor para su propia seguridad abandonar dichos programas y otorgarse medidas de fomento a la confianza dirigidas a superar las suspicacias que subsistan.

Así, el famoso túnel de Cachimbo, ubicado en el estado de Pará (Sierra de Cachimbo, Brasil), construido para realizar explosiones nucleares, fue lacrado ${ }^{39}$ en el gobierno democrático de José Sarney. ${ }^{40}$

Los presidentes Carlos Menem y José Sarney, en 1989, acordaron una serie de medidas adicionales de cooperación nuclear. Esa voluntad política del liderazgo democrático civil alcanzó un punto culminante en 1990, cuando ambos países emitieron una declaración sobre la política nuclear común, que entre otros aspectos considera el control de los materiales nucleares y la creación de una agencia de verificación de ambos países, la cual, se relacionará a partir de 1991 con la Organización Internacional de Energía Atómica, de un acuerdo suscrito el 13 de diciembre en Viena, por los presidentes Collor de Mello y Carlos Menem. ${ }^{41}$

En ese contexto, dichos Estados crearon la Agencia Brasileño-Argentina de Contabilidad y Control de Materiales Nucleares, ABACC (18 de julio de 1991), y establecieron un Sistema Común de Contabilidad y Control de Materiales Nucleares (SCCC). ${ }^{42}$ Estos pasos han probado los

39 Véase Gosman, Eleonora, "Admiten que la dictadura de Brasil planeó construir una bomba atómica", http://www.clarin.com/diario/2005/08/09/elmundo/i-02201.htm, y Cardoso, Óscar Raúl, "Una carrera secreta entre vecinos", http://www.clarin.com/diario/ 2005/08/09/elmundo/i-02203.htm.

40 Sucedió al dictador João Baptista Figueiredo. Su mandato duró desde el 15 de marzo de 1985 al 15 de marzo de 1990.

$41 C f r$. Rojas Aravena, Francisco, "Espacios para el diálogo. El fin de la Guerra Fría y la solución de conflictos en el Cono Sur", $D+C$ Desarrollo y Cooperación, núm. 5, septiembre-octubre de 2002, p. 21.

42 Declaración sobre Política Nuclear Común Argentino-Brasileña, Foz de Iguazú, 28 de noviembre de 1990. 
medios invaluables de desarrollo de confianza y cooperación entre Brasil y Argentina, y han creado un número de acuerdos de salvaguardias, protocolos y organismos subsidiarios. ${ }^{43}$

La ABACC (1991) es un organismo responsable de verificar si los materiales nucleares existentes en ambos países se están utilizando para fines exclusivamente pacíficos.

El Acuerdo Bilateral establece que las instalaciones brasileñas sean inspeccionadas por inspectores argentinos y viceversa. La ABACC actúa independientemente del OIEA, pero coordina sus actividades de contabilidad e inspección con este organismo. Esta maquinaria bilateral cuenta con la confianza de ambas naciones, mientras que la comunidad internacional está respaldada por la relación entre el OIEA y el ABACC establecida a través del Acuerdo Cuatripartito entre Argentina, Brasil, la ABACC y el OIEA. ${ }^{44}$

Cualquier anormalidad detectada como resultado de las inspecciones realizadas in situ por personal de la $\mathrm{ABACC}$ o a partir de datos registrados en los informes presentados a la ABACC por Brasil o la Argentina debe ser informada por la Secretaría a la Comisión de la ABACC, que podrá requerir del Estado parte que rectifique la situación en cuestión. El incumplimiento grave del acuerdo dará derecho a la otra parte a denunciar el Acuerdo o a suspender su aplicación, lo que deberá ser notificado al secretario general de las Naciones Unidas y al secretario general de la Organización de Estados Americanos. ${ }^{45}$

\section{B. Otros casos}

Otro caso avocado a la no proliferación es el latinoamericano, cuyo Tratado para la Proscripción de las Armas Nucleares en América Latina (Tratado de Tlatelolco) fue firmado el 14 de febrero de 1967 y entró en vigor el 25 de abril de 1969.

Las características del tratado de Tlatelolco son las siguientes:

43 Cfr. Carnegie Commission on Preventing Deadly Conflict, Preventing Deadly Conflict: Final Report, Washington, Carnegie Commission on Preventing Deadly Conflict, 1997, p. 81.

44 Cfr. Valle Fonrouge, Marcelo F., Desarme nuclear: regímenes internacional, latinoamericano y argentino de no proliferación, Ginebra, United Nations Publications UNIDOR, 2003, p. 80.

45 Véase artículo XIX del Tratado. 
- El Tratado no podrá ser objeto de reservas.

- El Tratado tiene carácter permanente y regirá por tiempo indefinido.

- Es el primer Tratado que define las armas nucleares.

- Es el primer Tratado de desarme lo cual obliga a las cinco potencias nucleares a respetar el estatus de desnuclearización de la región, así como a no utilizar o amenazar con utilizar armas nucleares en contra de las partes contratantes.

- El Tratado es enmendable. Cualquier parte contratante podrá proponer reformas, entregando sus propuestas al Consejo por conducto del secretario, quien las tramitará a todas las partes contratantes y a los demás signatarios. Se deberá convocar a una reunión extraordinaria para examinar propuestas. Una mayoría de dos tercios de las partes presentes y votantes se requerirá para la aprobación de cualquier enmienda. Las enmiendas deberán entrar en vigor después de que una mayoría simple de las partes contratantes las haya ratificado.

Más adelante, Argentina, Brasil y Chile, a los cuales se agregó México, promovieron una serie de enmiendas al Tratado de Tlatelolco con el objetivo de actualizarlo y hacerlo efectivo para toda la región. En agosto de 1992 las enmiendas fueron aprobadas y firmadas por los Estados partes en México, durante la VIII Sesión Extraordinaria de la Conferencia General del Organismo para la Proscripción de Armas Nucleares en América Latina (OPANAL). Una de las enmiendas prevé que la información que den los miembros del Tratado para demostrar el uso pacífico de la energía nuclear "no podrá ser divulgada o comunicada a terceros, total o parcialmente". La otra se refiere a la necesidad de evitar eventuales filtraciones a través de inspecciones. A partir de ese momento quedaba establecido que sólo el Organismo Internacional de Energía Atómica (OIEA) tendría la facultad de efectuar inspecciones especiales a pedido consensuado de los signatarios. Cabe señalar que las enmiendas propuestas fueron aprobadas con aclamación por los Estados parte del Tratado el 26 de agosto de 1992, en México, durante la IV Reunión de Signatarios del Tratado de Tlatelolco. Por su parte, el Congreso argentino ratificó el tratado mediante Ley núm. 24.272, promulgada el 7 de diciembre de 1993. Finalmente, en diciembre de 1994, Argentina, Brasil y Chile ratifi- 
caron el Tratado de Tlatelolco, alcanzando plena efectividad en el conjunto de la región un año después. ${ }^{46}$

\section{Negociación final}

Nosotros consideramos que una salida negociada es la mejor manera de solucionar esta controversia. Coincidimos con el director de la Agencia Internacional de Energía Atómica, Mohamed Elbaradei, cuando opinó que: "I don't believe there is a military solution to the issue. I think that a military solution would be completely counterproductive" (12-9-05).

Creemos que Irán encontró su ocasión ideal, en términos maquiavélicos, que tendrá que aprovechar siempre y cuando Ahmadinejad tenga la virtud, entendida como la capacidad de adaptación a las circunstancias, necesaria para negociar. Es decir, el gobernante iraní debe saber en qué momento apretar y en qué momento aflojar. Aparentemente va en ese camino. Sin embargo, todo depende de la necesidad que impulse a los actores a las negociaciones o al conflicto.

Estados Unidos tiene circunstancias internas particulares que podrían sumergirlo en una obligatoria negociación; el gobierno de Bush está finalizando y un giro demócrata es bastante probable.

Por otro lado, la negociación podría ser impulsada por Pekín, que "cuenta con una tradición no intervencionista de amplio espectro, tanto en relación con los países árabes y musulmanes como con Israel, y por ello es hoy en día una potencia con un prestigio particular". ${ }^{47}$

Finalmente, entendemos que una vez empezadas las negociaciones sobre su programa nuclear, el presidente Ahmadinejad debe dejar de amenazar a Israel, principal aliado de Estados Unidos en el Medio Oriente.

\section{CONCLUSIONES}

1. No se ha podido comprobar que el programa nuclear iraní tiene fines militares.

46 Véase Colacrai, Miryam, "La política exterior argentina hacia los vecinos durante los noventa", Documento de Trabajo núm. 1, Universidad del CEMA, Centro de Estudios Internacionales y de Educación para la Globalización, julio de 2004, p. 8. http://www.cema.edu.ar/ceieg/download/dt1_colacrai.pdf.

47 Soto, Augusto, op. cit., nota 6, p. 1. 
2. El tiempo que tardaría Irán en construir una bomba atómica sería de al menos tres años en el mejor de los casos.

3. Existe mucha suspicacia sobre los verdaderos fines del programa nuclear iraní, especialmente por el potencial energético que goza Irán, por ello, se le puede considerar como una amenaza si continúa llevándolo a cabo.

4. Existen condiciones internas en Irán que hacen casi imposible detener su programa nuclear.

5. La corrupción casi generalizada de la que es víctima el Estado iraní hace pensar que es muy probable que en el caso que obtengan una bomba atómica, se pueda trasladar la tecnología a grupos terroristas o inclusive venderlas al mejor postor.

6. A pesar de la guerra en Iraq, existe un segmento de la opinión pública de Estados Unidos que apoya las medidas tomadas por su gobierno, lo que conllevaría a una aceptación de un futuro conflicto bélico con Irán.

7. Si Irán persiste en llevar a cabo su programa nuclear sin impulsar medidas de fomento a la confianza, es muy probable que las grandes potencias se unan a Estados Unidos en un "ataque preventivo" a corto o mediano plazo o con una invasión a largo plazo. 